\title{
EN BUSCA DE DOS DÉCADAS PERDIDAS: LA NOVELA LATINOAMERICANA DE LOS AÑOS 70 Y 80
}

\author{
POR \\ María EugenIa Mudrovcic \\ University of Southern California
}

El trabajo que sigue se propone estudiar los modelos que decidieron el perfil genérico de la novela latinoamericana en los últimos veinte años. La primera parte se ocupa del modelo paraliterario o "novela política" y de sus variantes: la novela testimonial, histórica y periodística; y reserva la segunda parte a la descripción del modelo Trivialliteratur o "novela culinaria" (i.e., la novela policial, rosa y neo-picaresca [o novela de ghetto]). La correspondencia entre décadas y dominantes genéricas que propone el artículo trata de reflejar el grado de visibilidad que alcanzó la producción de uno y otro modelo dentro del campo cultural latinoamericano. Sin embargo, como sucede en todo intento de periodización, la división en décadas no deja de ser también una convención a la que se recurre para organizar la serie discursiva y dar, aunque más no sea, cuenta mínima de ella. En otras palabras: el corte tiende a describir los procesos de distribución y redistribución que experimentó el género pero está lejos de creerse una división excluyente y absoluta. Ya se sabe: toda lectura es selectiva. Habla según concepciones específicas del ser o del deber ser de la literatura y, a partir de estos criterios específicos de organización, construye su propia red de sentido. Al hacerlo, descarta otros corpus posibles, otros criterios de organización y, por supuesto, otras ideologías literarias. La lista (incompleta sin duda) de ensayos sobre los últimos veinte años del género que se incluye al final del artículo pretende subsanar estos (d)efectos de exclusión y, aun, de reducción que siempre pesan y enrarecen la conciencia a la hora de encarar un trabajo panorámico como éste. ${ }^{1}$

\section{Los años 70:}

Con mayor o menor insistencia la crítica ha tendido a asignar a los años 70 el rol de furgón de cola de los años 60 . En un gesto generalizado que resulta profuso a la vez que repetido, David Viñas, por ejemplo, compara "la euforia de los sesenta" con "la depresión de $\operatorname{los} 70$ " $(1984,13)$ y se refiere al mismo arco temporal con un lenguaje que no ahorra matices de decidida impiedad histórica: "del bum - escribe- desembocamos en el crash" $(1984,16)$. La lectura es, además de extendida, sin duda correcta, pero necesita saldar

\footnotetext{
1 Quiero asimismo agradecer a Susana Zanetti, Lucille Kerr, María Cristina Pons, Samuel Gordon y Rafael del Valle por sus comentarios y críticas a la primera versión del trabajo.
} 
algunas cuentas pendientes contraídas con el sentido que agregó a la historia la "nueva" década que acaba de terminar.

Por lo pronto, la densidad histórica que congestiona el inicio de los años 70 permite - sin necesidad de apelar a excesivos artificios - considerar este umbral como punto de partida del proceso literario que aquí nos proponemos describir. En un recuento apretado de hechos, baste apuntar que, en 1970, Salvador Allende se convierte en el primer candidato de una coalición de izquierda que accede a la presidencia de Chile elegido por voto popular. Un año después, mientras representaba al gobierno socialista en la embajada de Francia, Pablo Neruda recibe el Premio Nobel de Literatura: "He llegado hasta aquí con mi poesía y mi bandera," dice en el discurso de Estocolmo. Dos años más tarde, en 1973, el golpe de estado de Pinochet arrasa con Allende, con la democracia chilena, con Neruda y con una parte importante de la utopía revolucionaria según la había imaginado el gusto del consumidor sesentista.

Paralelamente al desarrollo político, una serie de acontecimientos culturales vino a alimentar también el sentimiento de clausura que caracterizó el conflictivo pasaje de una década a otra. En el marco del "primer balance crítico del boom latinoamericano," Angel Rama toma debida distancia de la década laureada señalando públicamente los componentes bestselleristas, elitistas y vedettistas que desprecia en la producción literaria de los años 60 (1972a; 1972b). ${ }^{2}$ También por aquellos años, el desenlace del caso Padilla fragmenta estrepitosamente el frente común de apoyo a la Revolución Cubana abortando, de paso, el proyecto editorial que el olimpo latinoamericano había consolidado en torno a la efímera revista Libre. A este conjunto suficientemente elocuente de disgregaciones debe sumarse, por último, la gota que rebalsó el vaso del descrédito sesentista: en 1972, a sólo cuatro años de Tlatelolco y a un año de la represión del Jueves de Corpus, Carlos Fuentes acepta representar en la embajada de Francia al cuestionado gobierno de Luis Echeverría, presidente del sexenio 1970-76 y secretario de Gobernación durante la masacre estudiantil del $68 .^{3}$

Bajo la presión de un contexto político cada vezmás radicalizado, la relación de fuerzas entre espacios públicos y espacios privados sufrió a principios de los 70 una reorganización estructural profunda e irreversible. Hasta este punto, la práctica literaria había convivido de manera más o menos armoniosa al lado de la práctica política. En los escritores más

\footnotetext{
${ }^{2}$ Llamamos "primer balance crítico del boom" al conjunto de textos que a principios de los 70 intentó por primera vez ofrecer una interpretación global de la literatura de los años sesenta y que, al intentarlo, virtualmente consideraba clausurados los alcances míticos de la década en cuestión. Como parte de este flujo que sólo dura algo más de tres años, Carlos Fuentes publica La mueva novela latinoamericana (1969), la UNESCO auspicia la edición del volumen colectivo América Latina en su literatura (1970), José Donoso publica Historia personal del Boom (1972) y Rodríguez Monegal recopila en El Boom de la novela latinoamericana (1972) una serie de artículos que originalmente había publicado en Plural.

${ }^{3}$ El caso Fuentes desencadenó una ola acalorada de impugnaciones dentro y fuera de México. La aceptación de Fuentes tuvo lugar en un momento de extrema sensibilidad política pero además y, sobre todo, sirvió para avivar las llamas de un debate que puso de manifiesto la plena vigencia de la antigua polémica entre intelectuales "apocalípticos" e intelectuales "integrados." Pueden seguirse los ecos de la cuestionada "cooptación" de Fuentes en la investigación elaborada por J. Ruffinelli, A. Pino Méndez, L.A. Ramos y J. Ventura Sandoval (1975).
} 
conocidos del campo latinoamericano era común que ambas esferas funcionaran como esferas escindidas o paralelas capaces de generar comportamientos y discursos que no se incomodaban mutuamente porque se creían independientes entre sí (Sigal 194-199). Traspasado el umbral de los años 70, esta coexistencia se tornó cada vez más impracticable (por lo menos en los términos poco conflictivos que había adoptado durante los años 60). La densidad histórica, por un lado, y la radicalización política que afectó los espacios públicos, por otro, hizo que la práctica literaria convergiera con la práctica política y que ambas compartieran finalmente un espacio común de enunciación. La coincidencia entre vanguardia estética y vanguardia política reconoció un territorio propio en lo que, a falta de una denominación acaso más adecuada, puede llamarse "novela política." El rótulo intenta dar cuenta del uso específico al que en los años 70 se sometió el espacio literario, es decir, trata de describir la posición central que alcanzó el ethos político durante una década en la que virtualmente llegó a controlar la producción global del sentido. "Todo es político" se ha dicho de los setenta y el emblema parece, por lo menos en parte y en cuanto a Latinoamérica se refiere, hacer justicia a la producción más visible del período (Baudrillard 36). En el compuesto que derivó la unión de literatura e ideología, lo político se comportó como topos o dato narrativo, pero también circuló como valor, punto de vista permanente y centro legitimador y organizador del sistema de referencias discursivas. Es el caso (paradigmático sin lugar a dudas) del Libro de Manuel (1973), novela clave del período que dramatiza este rito de pasaje (ya que cuenta la "conversión" estética de Cortázar) al mismo tiempo que explica cómo llegar al otro lado (dado que tampoco oculta una firme pretensión programática):

Durante muchos años [se lee en los preliminares] he escrito textos vinculados con problemas latinoamericanos, a la vez que novelas y relatos en que esos problemas estaban ausentes o sólo asomaban tangencialmente, hoy y aqui las aguas se han juntado, pero su conciliación no ha tenido nada de fácil, como acaso lo muestre el confuso y atormentado itinerario de algún personaje ( 7 ; el subrayado es nuestro).

El gesto de Cortázar es triple. En primer lugar, destina los derechos de autor a la ayuda de presos políticos. Junto con las palabras iniciales y el contenido mismo de la novela, esta decisión "militante" de Cortázar actúa como respuesta pública, mediatizada, a José María Arguedas, David Viñas y Oscar Collazos, escritores con los que previamente Cortázar había polemizado y ante los que había defendido la independencia ideológica y la pureza estética de la obra literaria. ${ }^{4}$ A sólo tres y cuatro años de estas sonadas polémicas, el Libro de Manuel significó en manos de Cortázar un gesto público de autocorrección que no pudo pasar desapercibido. De hecho, Viñas, que había atacado a Cortázar por no ser "ni chicha ni limonada" (1971, 129), ya en 1980 aplaudió sin ambages el "tránsito del primer Cortázar del culte de moi al actual del don de soi" $(1984,50)$. En segundo lugar, Libro de Manuel

\footnotetext{
${ }^{4}$ Antes de la retractación pública que significó el Libro de Manuel, el sentido común de la época había convertido a Cortázar en una suerte de paladín en la lucha por la defensa de la independencia ideológica de la obra literaria. Las posiciones que polemizaron con este primer Cortázar pueden seguirse en J.M. Arguedas y J.Cortázar (1969); Vinas (1969); O. Collazos, J. Cortázar y M. Vargas Llosa (1970).
} 
enseña que para Cortázar escribir una novela política no quiere decir olvidar las estrategias de la vanguardia estética y menos aún conceder a los efectos "tan temidos" del "tremendismo dostoievskiano al cuete" como en otra parte Cortázar rotula el registro de autocompasión populista que tantas veces adoptó la novela social de los años 40 y 50 (Cortázar 1967, 23). La sobreactuación del humor en Libro de Manuel apuntala sin duda este desvío voluntario y ayuda a diferenciar el programa cortazariano de la norma standarizada por el realismo socialista. En tercer lugar, un dato a tener en cuenta: Cortázar politiza la novela acercando el género al periodismo. Dicho de otro modo, el uso político de la escritura se ejerce en base a la desinstitucionalización del género novela. Al sacudir la escritura del ensimismamiento sobre lo literario y acercarla al margen de lo no literario, Libro de Manuel desmarca el centro del género y lo empuja a mirar hacia afuera y, al hacerlo, desinstitucionaliza, contamina lo literario, esto es, le niega autonomía discursiva.

A partir de los 70, el modo político de narrar que definió a la novela latinoamericana buscó reorganizar las estrategias discursivas del género en torno a una ideología fuertemente desinstitucionalizadora. Debido a la gramática de signo negativo que controló la extensa red del sentido setentista, una profunda crisis de autoridad afectó seriamente los focos de enunciación "fuerte" (es decir, institucionalizados) y desplazó el crédito, la legitimidad y el consenso hacia los discursos de los marginalia. Con relativa insistencia, el lenguaje reificado de la época se refirió a esos "centros" discursivos llamándolos poder, saber y verdad, tres categorías provenientes de la teoría foucaultiana que consciente o inconscientemente sirvieron para dar forma al campo semántico de la década. Testimonio del alto poder codificador que alcanzó el léxico posestructuralista en el sentido común culto de la época, Oscar Terán llamó a los 70 "Años Foucault," mientras Marshall Berman afirmaba convincentemente: Foucault "[is] a world-historical alibi for the sense of passivity and helplessness that gripped so many of us in the 1970s" (35). Lo cierto es que rápidamente liberadas de su paradigma teórico originario, las categorías foucaultianas constituyeron una mitología negativa de grandes pretensiones explicativas y normativas. En torno a ella, los 70 articularon un macrorrelato del centro (connotado como espacio de exclusión pero sin autoridad) que permitió impugnar la validez de los enunciados institucionalizados desde el Estado, la historia y la cultura alta, tres escenarios que la época consideró invariablemente teatros propios de "la ideología de la dominación." En sentido estricto, esta crisis de credibilidad pública e institucional, resulta un efecto rigurosamente histórico $\mathrm{y}$, como tal, debe ser leída en relación simétrica y necesaria con la dislocación de la ratio social que afectó a América Latina después que las dictaduras militares se reprodujeron masivamente en el continente a partir de 1973.

Producto emergente de la convergencia entre vanguardia estética y vanguardia política, la novela política de los 70 ideologizó los espacios del género y desvió la atención del código hacia lo no literario. Tratando de desinstitucionalizar los usos circulantes de la verdad, el poder y el saber, desarrolló proyectos narrativos que quisieron rivalizar sistemáticamente con los relatos del Estado, la historia o la cultura letrada. Los modos de dar forma a estos desvíos fueron muchos pero los que sin duda resultaron llamativamente visibles durante los años 70 y 80 fueron los que adoptó dicho desplazamiento en un ciclo de transición, la "novela del dictador," y en modos específicos como la novela histórica, la testimonial y la periodística. Todos formatos posibles, al cabo, de lo que acá tratamos bajo el rótulo común de novela política. En primer lugar, porque todas son formas paraliterarias, 
un marcado carácter documental e instrumental condiciona su escritura: la novela política siempre se escribe para algo. En segundo lugar, se trata de novelas que narran lo político como guerra, en la génesis se encuentra la confrontación: la novela política siempre se escribe contra algo. Por último, el uso político de estos textos exige por lo menos que se cumplan dos condiciones, lo político necesita formalizarse en la escritura pero también debe formatear la lectura: la novela política debe (para serlo) escribirse y leerse políticamente. ${ }^{\mathrm{s}}$

Como un modo de actuar directamente sobre el género, este cambio de funciones llevó a la novela a redefinir (y estrechar) a través del uso del documento su relación específica con la verdad, o mejor, como diría Foucault, con la voluntad de verdad. ${ }^{6}$ Considerando que la década anterior había entrenado el gusto para aplaudir una "imaginación" desbordante potenciada por la vanguardia estética, las estrategias discursivas que a partir de los 70 tendieron a reforzar el polo de credibilidad en lo narrado fueron sin duda (y para su momento) algo enfáticas cuando no decididamente estridentes. La novela política trataba por esta vía de diferenciarse y establecer nuevos contratos de lectura sobre una base de garantías y legitimaciones que no queria compartir muchos supuestos comunes con las redes contractuales vigentes en la década del 60 . El énfasis en referir lo real a través del uso del documento historiográfico, social o periodístico sirvió entonces tanto para diferenciar públicos como para consolidar un status epistemológico contradictorio, anfibológico, que la novela política no sólo no quiso inhibir sino que tampoco dejó de explotar. Todo esto viene en parte a explicar la importancia que concede a los marcos o a los umbrales de enunciados como espacios preferidos para hacer explícitas las relaciones particulares que dice guardar con la verdad. Muchas veces el nuevo contrato de lectura que establece entra en vigencia a partir del mismo título. Son los casos de obras como El caso Satanowski (1973) de Rodolfo Walsh; El caso Banchero (1973) o Uchuraccay, testimonio de una masacre (1983), ambas de Guillermo Thorndike; La novela de Perón (1986) de Tomás Eloy Martínez; Tejas verdes: diario de un campo de concentración chileno (1979) de Hernán Valdés; o 1492. Vida y tiempos de Juan Cabezón de Castilla (1985) de Homero Aridjis, para mencionar algunas obras que buscan la afiliación genérica a partir del rótulo $\mathrm{y}$, entre ellas, sólo a las que apelan a este recurso de manera más obvia. En muchos otros casos, el pacto de persuasión se refrenda en los preliminares de la novela; y téngase en cuenta que en este espacio de negociación del sentido deben incluirse desde las fotografías que "citan" la tragedia en La noche de Tlatelolco (1971), o en Nada, nadie. Las voces del temblor (1988) de Elena Poniatowska, hasta contratos de lectura lingüísticamente explícitos como los que aparecen en No habrá más penas ni olvidos (1980) de Osvaldo Soriano, en La aventura de Miguel Littín clandestino en Chile (1986) de Gabriel García Márquez, o en Aqui se habla de combatientes y de bandidos (1975) de Raúl González de Cascorro. Es además el caso del texto que firma "V.L." (i.e., Vicente Leñero) al comienzo de Los periodistas (1978):

\footnotetext{
${ }^{5}$ Básicamente el último punto resume las condiciones necesarias que permiten leer una novela alegóricamente.

${ }^{6} \mathrm{Hablamos}$ de verdad, poder o saber, usando las categorías foucaultianas que la época ayudó a reificar. Recurrimos a este léxico común aún a riesgo de incurrir en simplificaciones teóricas que pueden parecer imperdonables. Para un desarrollo extensivo de los problemas técnicos que supone trabajar con documentos novelísticos y novelas documentadas, remitimos a Foley (1986).
} 
El ocho de julio de 1976 el diario Excélsior de la ciudad de México sufrió lo que merece calificarse como el más duro golpe de su historia y tal vez de la historia del periodismo nacional. El episodio, aislado pero elocuente ejemplo de los enfrentamientos entre el gobierno y la prensa en un régimen político como el mexicano, es el tema de esta novela. Subrayo desde un principio el término: novela (9).

Desde este otro "tablero de instrucciones," Leñero explica el quién-qué-dónde-cuándo de la historia y también justifica el cómo: "amparado" por el género novelístico el "libro" promete decir la verdad, sin disfrazar nombres ni deformar escenarios. ${ }^{7}$ Por eso se le pide al lector que crea en un relato autolegitimado por el uso de documentos y en este lugar (al igual que en el resto del corpus) se invocan estos materiales como prueba de una verdad verificable extraliterariamente de la que el marco se sirve para autorizar el enunciado desde afuera ("toda la argumentación testimonial y novelística depende en grado sumo de los hechos verdaderos, de los comportamientos individuales y grupales y de los documentos mismos" [Leñero 9]). Por último, los prolegómenos también explican el por qué del relato: Leñero escribe Los periodistas para registrar y denunciar el caso Excélsior. (En el fondo o en la superficie, denunciar siempre aparece como el espacio de riesgo que negocia el sentido ético de la novela política.) Y frente a este riesgo, un gesto de responsabilidad algo heroica (la del autor) junto a la demanda de un pacto de lectura que acaso no puede inhibir un involuntario giro fáustico: "El novelista se siente obligado a asumir con plenitud su relato y sólo apela a la complicidad de sus lectores" (Leñero 9). La novela política siempre posiciona al lector y lo hace porque es un relato interesado que se sabe parte litigante en la lucha por la autoridad interpretativa de la historia que cuenta. De ahí que el tono muchas veces épico o la propensión a dividir el universo simbólico en grupos de "buenos" y de "malos" puedan considerarse estrategias propias de un género que habla del lado de una verdad sin poder (o sea, desde un lugar de enunciación no institucionalizado).

Hay otro dato sin embargo que debe tenerse en cuenta, la transacción que pacta la novela política con el lector, esto es, su promesa de decir la verdad o cierto grado de ella, tiene lugar sólo a nivel de la representación porque el suyo es un contrato condicionado. Por un lado, el género cuenta una verdad (documentada pero inverosímil) pero, por otro lado, elige contarla enmarcándola dentro de los márgenes estrictos de lo novelesco. Narrar una verdad poco verosimil y exigir al mismo tiempo la suspensión de la incredulidad que dictan las condiciones impuestas por el marco ficcional. En este cruce es donde el género negocia el sentido político del pacto ("en el punto en que la mentira dice la verdad...eso hace política a la obra" [107] escribe César Aira). Al pedir que el lector crea en su verdad increíble y hacer, sin embargo, depender esa verdad de un régimen de credibilidad que aparece sancionado desde lo literario, la novela política construye un espacio discursivo específico (autorizado justamente por tratarse de un espacio restringido o enmarcado) donde tiene posibilidad de hacer circular verdades sociales, históricas o coyunturales (ya sea que haya

${ }^{7}$ Dwight MacDonald llamo "bastarda" a esta forma de hacer periodismo "having it both ways, exploiting the factual authority of journalism and the atmospheric license of fiction" (Hollowell 44). La definición no nos parece del todo injusta, sin embargo, desde nuestra lectura este hibridismo o anfibología parece encontrar justificaciones que lo colocan más allá de la simple comodidad que denuncia MacDonald. 
adoptado el formato de novela testimonial, histórica o periodística) que no pueden circular libremente en otras redes de sentido. Explotando convenientemente los réditos simbólicos que derivan de esta doble pertenencia o esta doble legalidad, la novela política convoca los estándares del género para moverse con toda comodidad entre paradigmas a primera vista incompatibles: “¿Cómo narrar los hechos reales?" (184) es la pregunta que explícitamente se hace Respiración Artificial (1980) de Ricardo Piglia y sin duda es también la pregunta que está en la base de ese pacto contradictorio que rige tanto los umbrales o fronteras de la novela política como la génesis misma del género.

Si bien la novela política aspira en ciertos casos a actuar como ersatz o espacio sustituto de lo político, no quiere decir por ello que se trate de un género que quiera ilusionarse (ni pretenda ilusionar a otros) respecto de la posible capacidad performativa de sus enunciados. Raras veces confunde acción política con representación política. Por el contrario, la novela política trata de tomar la mayor distancia posible de aquellos discursos culturalmente centrados que sí reconocen una función claramente performativa. De este modo, mientras la novela trabaja con la representación de una verdad poco creíble, los discursos públicos con fuerte poder performativo no se preocupan tanto en hacer circular la verdad sino apuntan más bien a trabajar con la verosimilitud que es la estrategia que les garantiza llegar a ser discursos creíbles y eficaces. Estos últimos, por lo general, tienden a transformarse en discursos hegemónicos y ganan consenso porque, como diría Ludmer, se trata básicamente de discursos que "saben hacer que le crean" (254). Frente a este modelo, la novela política constituye un género sin muchas esperanzas performativas; en todo caso, las verdades inverosímiles que narra terminan cayendo bajo jurisdicción de una suerte de justicia imposible y pasan, como tales, a engrosar la zona utópica del género. ${ }^{8}$ Son casos "juzgados," es decir, se trata de casos formalmente cerrados o causas perdidas, historias, en fin, de derrotas y derrotados ("La historia se escribe por parte de quienes triunfan; los que pierden escriben novelas" [88] dice el narrador en Pepe Botellas (1984) de Gustavo Alvarez Gardeazábal).

La idea de que la novela política debe concentrarse en narrar las pérdidas y en mantener una relación de necesidad con el fracaso no sólo está ligada a la desconfianza que en los 70 - "años de reflujo" histórico los llamó Rama $(1986,464)$ - provocaron los discursos "oficiales" sino tiene que ver también con una moralidad histórica cuyo subtexto no explícito aparece controlado por una teleología que concibe la historia como repetición degradada del pasado: "Si la historia al comienzo se da como tragedia, después sólo se repite como oprobiosa comedia," en el primer caso es preciso ser "héroe" mientras que en el segundo sólo se necesita ser "un pobre payaso" (162). La cita pertenece a Juego de damas (1977) de Rafael Humberto Moreno-Durán pero la idea también aparece, aunque ligeramente

\footnotetext{
${ }^{8}$ Guillermo Thorndike escribió Uchuraccay: Testimonio de una masacre con la certeza de que narrar el caso no iba a ayudar a aclararlo ante la justicia pública. Para Thorndike, el asesinato de los ocho periodistas en Ayacucho era un ejemplo más de justicia imposible: "Con toda seguridad la culpa no la tenemos todos los peruanos, como dijo el informe, literario no judicial, del asunto. Porque si la culpa la tenemos todos no me explico francamente por qué murieron asesinados diez de los once testigos" (Roland Forgues 231-2). También Subercaseaux habla del elemento de "frustración por el no esclarecimiento" (188) presente en la novela testimonial chilena que registró la violación de derechos humanos durante el pasado régimen de Pinochet.
} 
modificada, en novelas tan distantes entre sí como Terra nostra (1975) de Carlos Fuentes y Noche de Califas (1982) de Armando Ramírez. Esta distribución más o menos indiferenciada prueba que el topos esconde un "lugar común intelectual," como lo llamaria Bourdieu, o, lo que es lo mismo, es un fuerte presupuesto de época. Como se sabe, la idea fue cristalizada en El dieciocho Brumario de Luis Bonaparte y refleja el rechazo que en 1851 provocó en Marx el triunfo de la contrarrevolución bonapartista. Además de compartir un mismo repudio ideológico hacia el presente histórico, diriase que existen otros elementos en el "original" marxista capaces de explicar el éxito retórico que tanto en los años 70 como en los 80 alcanzó este topos en Latinoamérica. En principio, la frase alude al sentido de repetición, de anacronía y, si se quiere, de decadencia que define el modo en que un presente en crisis piensa y evalúa su relación histórica con el pasado. De acuerdo a la descripción que hace Marx del bonapartismo, este tipo de crisis con el presente se desencadena toda vez que un personaje grotesco accede al poder y transforma a los sujetos sociales en testigos exteriores de ritos de autoridad y legitimación que invaden el espacio público con toda suerte de barroquismos burocráticos. ${ }^{9}$ Grotesco, escritura y ritos de exclusión histórica son, en efecto, las tres categorías "macro," los tres sistemas dominantes de representación, que sirven para tipificar el sentido de dislocación e inversión social según aparece narrado en la novela latinoamericana de las últimas décadas. Desde Yo el supremo (1975) de Roa Bastos a La novela de Perón de Tomás Eloy Martínez, pasando por La noche de Tlatelolco (1971) de Elena Poniatowska, La vida entera (1981) de Juan Carlos Martini o Noticias del Imperio (1987) de Fernando del Paso, insistentemente la novela política compone historias de derrotas y en la base de este proceso de fabulación inscribe su gesto de cura ideológica: querer, a partir de ellas, "pronosticar," es decir, alegorizar, un presente crítico que se vive con malestar y rechazo. Se trata entonces de novelas de doble linaje. Por un lado, amplifican esa teleología de la repetición degradada a la que alude la archicitada frase de Marx. Por otro, acceden (y asaltan) los documentos de lo real con la franquicia que favorece una situación enunciativa que se sabe alternativamente amparada y desamparada a causa de la distancia histórica y/o social que separa la enunciación de los enunciados reales.

Reapropiarse de los sentidos, sociales e históricos, significó entonces trabajar consistentemente por des-emblematizar los discursos de lo real. Precisamente Benjamin ya había llamado la atención sobre los riesgos derivados de un tipo de pobreza de carácter simbólico que en tiempos del fascismo llegó a afectar por igual a espacios públicos y privados. "Pobreza de la experiencia: no hay que entenderla como si los hombres añorasen una experiencia nueva. No; añoran liberarse de las experiencias, añoran un mundo entorno en el que puedan hacer que su pobreza, la externa y por último también la interna, cobre vigencia tan clara, tan limpiamente que salga de ella algo decoroso" (172). No basta entonces con que los discursos culturamente centrados aspiren sólo a la verosimilitud, necesitan ser además discursos desembarazados de acontecimientos, es decir, discursos livianos, prolijos, abstractos y liberadores, marcas retóricas que, según Benjamin, articulan la estética despojada de tono ligero que define un tipo de discurso público candidateable

\footnotetext{
${ }^{9}$ Para un análisis más detenido de El dieciocho Brumario remitimos a Larsen (1-31). La lectura de este trabajo nos ha sugerido muchas de las pistas que seguimos en esta parte del artículo.
} 
para alcanzar rápido consenso. Contra este modelo que valora el decoro y odia la promiscuidad, la novela política monta una gramática reactiva de lo lleno, lo fétido y lo sucio en base a un programa que promueve, entre otros usos políticos, romper violentamente con los mitos del discurso disciplinado, "barbarizar" la verdad, saturar los vacíos con el incidente histórico, explicitar los sobreentendidos de la historia y corporizar, esto es, llenar de contenido, esos valores estetizados que siempre justifican la iconografía de las grandes retóricas colectivas. A este nivel, la politización de la novela trabajó básicamente sobre dos estrategias discursivas. Primero, buscó des-estetizar los discursos de lo real. Segundo, quiso reescribir la historia ya no como escatología de una idea sino más bien como historia escatológica. Después de las lecturas de Foucault y Bataille, la novela política que emerge a partir de los 70 construyó en torno al cuerpo una de las alegorías más sólidas y recurrentes de su discurso de resistencia. El cuerpo fue el lugar per se donde se purgó lo real, donde se lo des-metaforizó ("el discurso de la acción es hablado con el cuerpo" [52] se lee previsiblemente en Respiración artificial). Las historias que cuentan las novelas políticas no sólo son historias que huelen mal, sino también son historias que con su carga de humores, flatos, infecciones y detrito buscan, literalmente, ensuciar los grandes mitos de cohesión, esos universales glorificados y despolitizados que el discurso de la civilización autoconsagra como valores eternos. En este punto cabe acotar que el cuerpo politizado tiene un valor diferencial respecto del cuerpo erótico como figura de placer y hedonismo que ocupó un lugar central en la novela de los 60. A partir de los 70, el cuerpo se politiza como signo, es decir, cambia de función y resignifica su campo semántico: de centro de goce sexual pasa a ser centro de uso perverso debido a que, básicamente, la novela política recompone en torno a este sintagma un "uso corporal del poder como fuerza y violencia" (Ludmer 184). En lugar de la operación que estiliza una función natural del cuerpo y exalta lo sexual como signo de goce (tal como procedió la novela sesentista), el gesto político de la década siguiente tiende contrastantemente a desfuncionalizar el cuerpo y a enfatizar sus discontinuidades a partir de la exasperación de cualquier relación posible que sea capaz de entablar con lo mórbido. Para ello, echa mano de la estrategia irritativa propia del punto de vista des-emblematizador que define al grotesco. Los casos puntuales que pueden citarse son varios. En Los periodistas, por ejemplo, Leñero no sólo narra el triunfo de los reginistas sobre Julio Scherer García en forma de farsa sino que termina a su vez "coronando" el final de la farsa con una marea de excrementos que literal y vengativamente sepulta a la oposición triunfante. En No habrá más penas ni olvido, Cerviño fumiga Colonia Vela con un avioneta cargada de materia fecal mientras abajo los dos bandos peronistas luchan a brazo partido por la posesión física y simbólica de la intendencia. Palinuro de México (1980) de Fernando del Paso es, casi, un totem del cuerpo opaco, una suerte de enciclopedia que en lugar de ordenar el dato médico lo desordena potenciando todos los cruces imaginables entre lo coprológico y lo anatómico, mezclando la genitalidad con la interdicción, confundiendo lo obsceno con la porno-violencia del 68 en un registro arqueológico-erudito que "explica" el cuerpo humano al mismo tiempo que lo pone en escena. Otra especie de perversión del sentido es, sin embargo, la que protagoniza Gabriel Canales, el militante de En este lugar sagrado (1976) de Poli Délano, que procede a componer una historia personal de la política chilena mientras espera salir del baño de un cine donde quedó atrapado el 10 de septiembre, donde también pasó encerrado (es decir, resguardado) el golpe militar del 11 y de donde cree (irónicamente) quedar en "libertad" al ganar las calles del Chile de Pinochet. Puede decirse 
que el baño también actúa como marco en Breve historia de todas las cosas (1975) de Marco Tulio Aguilera Garramuño. En esta novela, la relación entre discurso corporal de la resistencia y discurso des-estetizador de la historia resulta más o menos transparente, especialmente cuando el Historiador-literato Mateo Albán decide contar las escenas menos líricas de nuestra "historia universal de la infamia" encuadrando decorosamente su narración en el baño de la prisión-panóptica donde escribe:

[Mateo Albán] tomó asiento en el inodoro, puso una tabla sobre sus piernas, prendió una vela y escribió lo siguiente: $Y$ entonces cuando llegaron los gringos hubo progreso (121)

En este punto hay que considerar, sin duda, otra variable de novela política que también trabajó el mismo principio des-emblematizador. Se trata de la línea discursiva que se especializó en investigar a los héroes de los panteones nacionales y que, apegada fuertemente al documento historiográfico, construyó una nutrida galería fascinada con héroes jubilados de la historia olímpica y obsedida de personajes derrotados y menesterosos. Este tipo de novela despreció tanto el aura de lo épico como el aura de la historia y trabajó, más bien, para narrar personajes históricos que son tan anti-heroicos como anti-quijotescos y lo son, básicamente, porque nunca mueren desangrándose en un campo de batalla sino que siempre se extinguen de "muerte natural" supurando humores inclasificables en una cama o en una letrina. En otras palabras, no mueren (redimidos ni sublimados) peleando por defender una idea sino mueren (vulgares, corruptibles y olvidados de toda aura) tratando de sobrevivir a las demandas materiales del cuerpo. Detrás de esta inversión que cambia la relación de fuerzas entre cuerpo/idea institucionalizada por el discurso historiográfico dominante puede localizarse entonces la movida política que persiguieron muchas novelas (y no sólo aquellas que han sido canonizadas como novelas históricas) que circularon durante los 70 y los 80. La lista que sigue corre el riesgo de parecer, por lo mismo, inevitablemente arbitraria o incompleta. En cualquier caso piénsese, sólo como ejemplo más o menos a mano, en las miserias físicas del Belgrano gotoso y en retirada según lo imagina la historia de Sota de bastos, caballo de espadas (1975) de Héctor Tizón. O en el Maximiliano que Fernando del Paso documenta en Noticias del Imperio, enfermo de diarrea y pestes venéreas que le carcomen el cuerpo y le hacen expurgar líquidos verdosos y fétidos. Tampoco el Perón de Tomás Eloy Martínez, infértil y moribundo, es más afortunado en cuanto a achaques corporales así como tampoco parece serlo el cuerpo hidrópico, pestilente y en progresiva descomposición de Felipe II en Terra Nostra.

Y frente a estas historias, El general en su laberinto (1989) de Gabriel García Márquez recarga todo el peso de las desdichas sobre la figura endeble de Bolívar ("Parece que el demonio dirige las cosas de mi vida" [9] escribe Bolívar a Santander y la frase sirve desde el epígrafe para anunciar la cadena de fatalidades que persiguen a este otro general retirado que con tanta naturalidad pasa a engrosar las filas de la fauna de militares retirados garciamarquianos). Politicamente derrotado, exiliado, enfermo (no se sabe bien de qué), impotente, insomne, precozmente envejecido, desbordado de flatulencias, olores y sudores, Bolívar asiste además al afantasmamiento de su propio cuerpo: afantasmamiento simbólico (los pintores no parecen ponerse de acuerdo con el cuerpo que le "inventan") y afantasmamiento físico (literalmente el cuerpo se le encoge y García Márquez registra milimétricamente este proceso de reducción o desgaste material). Completando el cuadro 
de la derrota física, el general actúa como militar desempleado al frente de un ejército libertador que ya no pelea, podrido de gonorrea y de aburrimiento, pero que aún sigue conservando, mal que le pese, fama involuntaria de ejército arrasador: no tanto por el respeto que impone en las armas sino más bien porque a su paso la gente quema todo lo que toca como una forma preventiva de evitar cualquier contagio con la peste. Sin embargo la ironía mayor de la historia reside en el hecho de que el "Libertador de América," como otro Teseo en su laberinto, se convierte en un fugitivo que huye de la deformación en que ha degenerado su propia idea (" $i Q$ ué cara nos ha costado esta mierda de independencia!" $[174]){ }^{10}$

Detrás de este movimiento masivo que des-institucionaliza la historia, que invierte las relaciones emblemáticas entre cuerpo/idea y héroe/traidor, que barbariza los usos de la verdad y que trabaja por reconvertir la "pobreza de la experiencia" propia de los discursos institucionales que se apropian de lo real; detrás, en fin, de estas estrategias de sobrevivencia que en tiempos de reflujo o hibernación histórica buscan reapropiarse y articular la red de contenidos históricos y sociales, actúa como subtexto una cadena de tendencia fuertemente anti-intelectual ("el cogito, ese huevo infernal ... nos llevó directo a Mi lucha" (247) se lee en Respiración Artificial). En parte, este subtexto viene a explicar por qué en la novela política de estos años, el discurso de la razón y la escritura, su extensión emblemática, siempre engañan o conducen a pistas equivocadas. Como catalizadores de la desconfianza discursiva diríase que tanto la razón como la escritura parecen relegados a ocupar un lugar ineludible al lado del error. Pero además de llenar estos espacios vacíos de poder y credibilidad discursiva, importa señalar más bien que esta base anti-intelectual sirve también para estrechar la relación que la novela política - tanto en su formato testimonial como en su formato periodístico o histórico - parece entablar con el denso metarrelato que Halperín Donghi llamó certeramente "crisis general de la civilización" (82).

\section{Los años 80:}

Los años 80, también conocidos como la "década perdida," fueron años de parálisis y fuerte contracción económica para toda Latinoamérica. Desde principios de la década, el alza de las tasas internacionales de interés, la caída de los precios del petróleo, la fuga de capitales nacionales y la creciente dolarización de las economías regionales acentuaron el endeudamiento, la recesión y la reducción del gasto público, tres signos que, por sí solos, dan sobrado sentido al rótulo con el que la CEPAL identificó a la década. Presionados por

\footnotetext{
${ }^{10}$ Frente a estas novelas que se concentran en personajes históricos incorporados a los panteones patrios, puede ubicarse el corpus de novelas que trabajan con personajes históricos no centrales (y muchas veces ignorados) por los discursos historiograficos nacionales. En contraste con los "héroes" oficiales que mueren en la cama, los personajes históricos marginados de la historiografía oficial mueren en acción o, para citar la retórica escolar, defendiendo con sangre las mejores ideas. Por lo general este último grupo está formado por aquellas novelas que tematizan el ciclo de "la violencia" en Latinoamérica: desde el Bogotazo hasta el 68 y los movimientos universitarios, pasando por los golpes militares y las dictaduras del Cono Sur, los movimientos guerrilleros de los sesenta y setenta, la represión y los exilios. Las figuras históricas más recurrentes de este ciclo narrativo son el Che, Camilo Torres, Jorge Eliécer Gaitán, Salvador Allende (+ Pablo Neruda).
} 
este tipo de transformaciones (transformaciones que guardan estricta relación con los procesos de internacionalización del capital por entonces en boga), los distintos Estados latinoamericanos implementaron una nueva receta liberal que ayudó a dar forma a un fenómeno relativamente global aunque no siempre sincrónico. Más tarde o más temprano, casi toda Latinoamérica terminó sin embargo aplicando proyectos económicos que además de impulsar la "racionalización capitalista" de los aparatos productivos y estatales, buscó la "integración subordinada" de los capitales nacionales a las redes internacionales de capital (Gilly 24). A grandes rasgos puede decirse entonces que a lo largo de la última década la misma tendencia neoliberal gestó como resultado mediato un doble juego de sustitución y cambio que aún no termina de cumplirse: sustitución del "estado protector" por un "estado de exclusión" y sustitución de una economía de la productividad por una "cultura de la especulación y el espectáculo" (García Canclini 248). ${ }^{11}$

En el plano político, la década se identifica tanto con los procesos de democratización que involucraron a varios países del Cono Sur como con la integración de grupos regionales (léase, Contadora y el Grupo de los Ocho o Grupo Río) a través de los cuales el área buscó consensuar respuestas comunes en torno a problemas puntuales relacionados con la deuda externa o con negociaciones de paz en Centroamérica. Los 80 fueron, sin duda, un período que privilegió las salidas políticas pautadas en base a la concertación, la integración y el consenso. La impronta de este circuito consolidó en torno a "democracia," primero, y a "pluralismo," después, dos núcleos fuertes de legitimación discursiva que fueron promovidos hasta ocupar un lugar central en la producción del sentido de la época. Aunque cabe aclarar en este punto que, si al principio de la década trabajar por la democracia formal pudo significar más o menos lo mismo que trabajar por el mejoramiento de las condiciones sociales de la mayoría, hacia el final de la década la aplicación del modelo neoliberal dejó cada vez más claro que hablar de democracia formal no era del todo equivalente a hablar de democracia social (Zermeño 1990).

Siguiendo con esta suerte de recuento congestionado, puede decirse que tampoco el campo cultural escapó al monopolio simbólico de los mismos "lugares comunes intelectuales" que sirvieron para legitimar los espacios económicos y para hacer audibles sus retóricas políticas. Sin duda la marca de concertación y el componente integrador y democratizador actúan en la base de la gramática de sentido positivo que en los 80 buscó insistentemente diluir toda relación de oposición y cambiar el signo negativo que identificó el mapa cultural de la década anterior. Los "años Foucault" se transformaron en "años Bajtin" y el matiz de resistencia que ideologizaba la categoría (excluyente) de "el otro," tan popular en los 70, sobrevivió ahora blanqueada y procesada en la categoría (inclusiva) de "lo heterogéneo," preferida sobre todo a partir de los 80 . EI eje de sentido tendió entonces a desplazarse desde el polo de una ideología de la resistencia al polo de una ideología que busca "desdramatizar" toda confrontación, confundir cuando no trivializar las categorias productoras de diferencias económicas y sociales y, una vez aplanado ( $y$ atomizado) el terreno de la dramatización simbólica, busca crear, por fin, la ilusión de que tanto el "pluralismo" como la "integración" horizontal y polifónica se han convertido en condiciones políticas, si no

\footnotetext{
" Para componer este cuadro diagnóstico de los 80s, además de Gilly (1986) y García Canclini (1990), hemos consultado a Zermeño (1990) y Habermas (1986).
} 
eternas, por lo menos en cuasi-absolutas. "Ya nadie sabe lo que es subversión" (122) dice Jameson $y$, en este punto, cualquier vestigio de polifonía inicial queda formalmente olvidado bajo el peso arrollador de "la lección posmodernista [que] es una lección posdualista" (123). ${ }^{12}$

De este modo, si los años 70 imaginaron cómo "salir" o cómo resistir, contrastantemente los interrogantes que en los 80 acceden a un primer plano de interés tratan más bien de responder: "¿cómo institucionalizarse, como "entrar,' cómo dialogar con el Estado? Esa" - según Piglia - "es la versión cultural de la problemática que los medios definen como 'vivir en democracia"' (1990, 175). La marcada tendencia hacia la institucionalización que manifestaron los espacios públicos, afectó asimismo los espacios internos de lo literario reorientando, consecuentemente, el sentido dominante del género novela. "La era del orden es el imperio de las ficciones," escribió Valéry, y en un intento gradual pero consistente por extender sus efectos de territorialización sobre el campo cultural, esta corriente institucionalizadora tendió a reordenar los espacios discursivos al mismo tiempo que buscó reafirmar la autonomía del género en torno a lo literario. Dicho de otro modo, la esfera pública de los 80 tendió otra vez a dividir las aguas entre literatura y política, aguas que, según la imagen acuñada por Cortázar en el Libro de Manuel, habían logrado sobrevivir indiferenciadas bajo jurisdicción común de la novela política. Como efecto previsible de lo mismo, la novela de los 80 mostró entonces una tendencia paulatina a desideologizar sus espacios discursivos internalizando los usos políticos que habían sido convencionalizados por el género durante la década anterior. Poco a poco y en un proceso de autonomización que aún no termina de definirse, la dominante del género tiende a abandonar el terreno de lo paraliterario flexibilizando los lazos explícitos que ligan la novela a la investigación y relegando su función de exhumación y rescate del documento histórico y social a un segundo plano de interés discursivo. Junto a esta tendencia que mediatiza la relación literaria con lo real, toma fuerza un programa simétrico que busca "especializar" el género y estrechar (y aún explotar) los vínculos específicos que la novela mantiene con el verosímil literario. En lo que puede considerarse un intento por re-estetizar los espacios interiores del género, esta línea narrativa no sólo se mueve con toda comodidad en el espacio (antes despreciado) del lugar común sino que además redefine sus límites a partir del trabajo específico que encara sobre un doble estereotipo. Estereotipo genérico: porque esta suerte de novela secular y "culinaria" elige explorar formatos fuertemente codificados como la novela policial, el melodrama, la parábola, la picaresca, el western o la novela gótica. Y estereotipo social: porque además trabaja sobre figuras marginales más o menos arquetípicas

\footnotetext{
${ }^{12}$ No es nuestra intención traer aquí a un primer plano el debate modernismo-posmodernismo, sólo hacemos referencia a la emergencia de esta "nueva" gramática de sentido en el marco de nuestro recuento de cambios visibles ocurridos en la década del ochenta. Apuntamos sin embargo, sólo en nota, lo que de alguna forma $u$ otra ya ha apuntado la crítica previamente. Si aceptamos con Zermeño que "el asunto de la igualdad social (máximo referente del humanismo, junto con el cultivo de la razón, la cultura, etcétera) no es un elemento intrínseco del modelo neoliberal, sino que tiene que ser reintegrado a ese modelo como ideología" $(1990,228)$, diríase que el posmodernismo parece un relato de por sí candidateable para ocupar este espacio vacante. El debate sobre el posmodernismo en América Latina está lejos de haber concluido, para un tratamiento más específico del tema remitimos a Zermeño (1988); Ruffinelli (1990); Sarlo (1991).
} 
que evocan redes precisas de sentido como la subcultura del califa, la prostituta, el lumpen, el exiliado, el homosexual, el judío, el indígena, la mujer, el macho, etc. ${ }^{13}$

El primer lugar donde se hace explícita la secularización o re-institucionalización del género es precisamente en los marcos, en los mismos bordes de los enunciados. Percibidos como espacios apropiados y convencionalizados por la novela política, los umbrales se convierten entonces en materiales parodiables y objetos parodiados de la novela culinaria. Desde el principio, el recurso a la parodia señala esta suerte de propiedad para reírse de ella, pero también enseña que junto al cambio de funciones la parodia anuncia el pasaje de un sistema literario a otro. Por eso toda vez que la novela culinaria usa el procedimiento, lo usa por dos razones más o menos explícitas: para tomar distancia efectiva respecto de los programas de la novela política y para renegociar espacios propios entre oferta y demanda. Es decir, para fundar un nuevo pacto de lectura. En la medida en que los preliminares del género "desambiguan" los enunciados y los liberan de todo vínculo extraliterario, están imponiendo un nuevo patrón de suficiencia y autonomía literarias que busca retraer el ciclo de recepción al momento previo en que entró en vigencia el pacto de lectura que la novela política estableció con lo real. El prólogo de Juego de Damas, primer volumen de la trilogía Femina suite de Rafael Humberto Moreno-Durán, parece un buen ejemplo de este tipo de registro burlesco detrás del cual la novela aspira a normalizar (esto es, a re-institucionalizar) su "antigua" relación unidimensional con lo literario:

Rigurosamente cierto: cualquier parecido de situaciones y personajes de esta obra con otros de la llamada realidad no deja de ser pura coincidencia. Querer hallar, pues, identidades precisas y obligadas entre una y otros constituye no ya un flagrante acto de paranoia sino de mala fe. Palabra de honor. (9)

La admonición preliminar está donde está para incomodar, adelgazar y, de ser posible, también frenar cualquier impulso que promueva politizar el espacio de recepción. Sobre todo, está donde está para resistir que Juego de damas sea leída como alegoría nacional o roman-a-clef, dos lecturas que representan grados intermedios en la cadena de sustituiciones que avanza hacia la secularización del género. Sin embargo, al ubicarse donde la novela se ubica, esto es, al filo de una transición de lógicas discursivas, resulta probable que la obra sea leída justamente como lo que dice no ser. Moreno-Durán lo sabe, de ahí que estos preliminares (a la manera de chiste privado) fomenten también la doble moral que parece colarse debajo del riesgo de saber que toda admonición resulta, en cualquier caso, ineficaz de antemano.

${ }^{13}$ El término "novela culinaria" proviene de Jauss que lo utiliza para referirse "al mero arte de entretenimiento." Desde el punto de vista de la teoría de la recepción, el arte culinario se caracteriza "por el hecho de que no requiere ningún cambio de horizonte, sino unas expectaciones que son indicadas e incluso cumplidas por una predominante tendencia del gusto, satisfaciendo el deseo de reproducción de lo bello habitual" (Jauss 175). En América Latina, las condiciones mínimas que garantizan el consumo de arte culinario tal como lo describe Jauss parecen cumplirse al pie de la letra. En efecto, la novela latinoamericana emergente en los 80 que aquí llamamos "culinaria" se caracteriza tanto por la legibilidad o "facilidad" de sus proyectos narrativos, como por la linealidad tranquila de sus relatos. Dos motivos que explican a primera vista el éxito de público que esta variante ha tenido en el mercado latinoamericano. 
Otro lugar donde vuelve a hacerse explícito este proceso de autonomización y reinstitucionalización literaria es en la tendencia que muestra el género a usar fórmulas o formatos codificados. Conocidos también como géneros menores o Trivialliteratur, los moldes que formatean la policial, el melodrama, la picaresca o el western, parecen evocar una suerte de "escritura mecánica" ante la cual, se dice, los autores sólo "componen, descomponen o recomponen los ejes del relato y los personajes como en una cinta transportadora" (Mandel 9). Una literatura que, por lo mismo, también ha circulado y circula como forma básicamente irreflexiva de hacer y leer literatura. Una literatura, en fin, que tiene la mala reputación de transformar toda historia en historieta, o de reducir cualquier lugar en lugar común del género. Tratando de ir más allá de lo que parece ser una lucha de jurisdicciones entre cultura alta y cultura baja, cabe apuntar que todos estos formatos comparten una base común de datos a partir de la cual es posible abstraer un modelo global aplicable a todo el conjunto. Poco más o menos, puede decirse que todos estos formatos prescriben el final feliz, por ello se dice que son narraciones seguras y socialmente integradoras (Mandel 67). El desorden de la historia (se trata, sin duda, de géneros crueles) termina sin embargo con el triunfo irremediable del orden (son, sobre todo, géneros utópicos, consoladores). $\mathrm{Y}$ el fuerte elemento realista que dicta el verosímil literario siempre aparece combinado con una dosis compensatoria de absurdo, irrealidad o irrisión (son géneros basados en los dobles estándares, en ellos todo signo es doble y debe ser leído como doble: verdad-mentira, legalidad-ilegalidad, norma social-necesidad personal, ingenuidad-cinismo). Por último, se trata también de géneros sentimentales porque, parafraseando a Kundera, podría decirse que apuestan al sufrimiento sabiendo que previamente lo han convertido en un valor explotable en sí mismo (194). ${ }^{14}$

En América Latina, el primer espacio donde se debate la sustitución de este modelo global y el primer espacio donde se dramatiza la transición entre novela política y novela de fórmula es, sin duda, la novela policial. Mitad escritura política y mitad "escritura mecánica,"la novela policial latinoamericana representa una zona privilegiada de intersección y negociación de sentidos entre literatura y política. No se trata sin embargo de una zona franca de simetrías o discursos intercambiables. A diferencia de la novela política que potencia el uso ideológico del espacio literario, la novela policial procede más bien a hacer un uso literario del dato político, esto es, procede a transformar la política en coartada o en lugar institucional del género. Dicho de manera más gráfica: la distancia que separa la novela política de la policial es la misma distancia que separa el despliegue documentalista del caso Excélsior que encara Vicente Leñero en Los Periodistas, del desarrollo policial que elige Federico Campbell para contar el mismo acontecimiento en Pretexta (1979). Por eso, en la medida en que la policial privatiza el referente político y lo internaliza como topos, puede pensarse que representa un avance visible hacia la secularización o autonomización de la novela según la venimos describiendo en esta parte del trabajo.

\footnotetext{
${ }^{14}$ Este modelo global toma en cuenta los dos relatos que se consideran básicos en la composición de la literatura popular contemporánea: el relato policial y la "literatura romántica femenina." Mandel acuerda con lo anterior cuando en su análisis del relato policial hace derivar de un mismo tronco genérico tanto a la picaresca, como al western y a la novela de espionaje. Además del citado texto de Mandel, remitimos en este punto al trabajo de Sarlo sobre género sentimental.
} 
"Nuestro continente se cuenta bien ... con técnicas de novelanegra" (1987a, 40) escribe Paco Ignacio Taibo II, uno de los escritores responsables de la "bestsellerización" del género en México. Primer dato entonces a tener en cuenta: la novela negra, atrincherada en su triple mitología de violencia, sexo y dinero, desplaza de la tradición latinoamericana a la novela clásica de enigma. (Los avances que en los 70 llevaron a cabo Juan Carlos Martini, Osvaldo Soriano, Juan Carlos Martelli o Andrés Rivera representan un precedente fuerte en este sentido, sobre todo si se piensa en el prestigio que gozaba por entonces en el Río de la Plata la línea clásica capitaneada por Borges y Bioy Casares.) Segundo dato a tener en cuenta: en América Latina la contaminación entre poder y crimen infiltra de tal ambigüedad y cinismo al género que la fórmula termina cambiando sus preguntas arquetípicas. En La vida misma (1987b), mezcla de policial y western de Paco Ignacio Taibo II, el protagonista José Daniel Fierro (a su vez escritor de novelas policiales) metacomenta: "pocas veces se va a preguntar uno quién los mató, porque el que mata no es el que quiere la muerte. Hay distancia entre ejecutor y ordenador. Por lo tanto, lo importante suele ser el por qué" (142). Tercer dato a tener en cuenta: el orden terminal que prescribía el modelo rara vez se restablece y los finales de la novela policial latinoamericana manifiestan una fuerte tendencia a quedar inconclusos, sin solución ni reaseguro social. Osvaldo Soriano que practica religiosamente esta regla de oro en sus novelas, nunca deja pasar oportunidad sin denunciar esta suerte de frustración técnica que atribuye a una insuficiencia imperdonable de lo real: "Argumentos sobran, pero el epílogo siempre queda trunco." - escribe en "Policiales sin final feliz" (1987)_ "Hay delincuentes (miles, no hay lugar donde haya más), pero nadie los escarmienta y es imposible planear un guión con final feliz" (223).

El recuento, aunque incompleto, permite de todas formas concluir que la aplicación del modelo que lleva a cabo la novela policial latinoamericana resulta ser, por definición, una traducción defectuosa del original. Sin embargo el negocio de la fórmula no está precisamente en ocultar ese defecto. Antes bien, la novela policial latinoamericana resalta el defecto y lo explota como forma emblemática de su versión particular del modelo. Poco o nada, si bien se mira, puede hacer por la tradición universal una novela policial que de hecho carece de detectives profesionales. Los personajes de Soriano son héroes por equivocación o casualidad que entran en el ingrato tráfico de defender la cosa pública con una generosidad no planificada: muchos son locos o están borrachos. Por su parte, Héctor Belascoarán Shayne, el improvisado y pos-burgués agente del bien que inventa Paco Ignacio Taibo II, ingresa al negocio de la justicia mexicana como si repitiera votos de penitencia voluntaria sólo comparables a los que en otros tiempos cumplió el Quijote en Sierra Morena ("Ser un detective en México es, por supuesto, un chiste" [6] dijo Ilán Stavans con razón). Lo cierto es que, lejos del rigor eficaz y de la estetización realista que rige un modelo esencialmente preocupado en lograr que el lector crea lo que cuenta, la versión policial latinoamericana tiende a dar vuelta los dobles estándares (retóricos e ideológicos) que controlan la fórmula, al tiempo que redobla esfuerzos para que el lector no crea (o, por lo menos, no tome en serio) el contenido vistosamente defectuoso que vacía sobre el lecho de Procusto que es, al fin de cuentas, el género policial en América Latina.

La sobreactuación de una economía de la ineficacia, por un lado, y la tendencia a una estetización falsificadora del modelo, por otro, son entonces claves recurrentes en la novela culinaria de los 80 en América Latina. La primera tiende a contar el crimen mientras que 
la segunda suele ser la forma de contar el amor que adoptan muchas de nuestras versiones también imperfectas del género rosa. En este sentido, la línea argumental de Melodrama (1983) de Luis Zapata sigue, por ejemplo, los nodos básicos del folletín (persecusión, secretos, pasión prohibida y reconciliación social como botón de seña para el final feliz que exige la fórmula) pero, en lugar de usar estos componentes para tranquilizar y dar previsibilidad al desarrollo del contenido, Zapata los usa para montar una historia de amor protagonizada por una pareja homosexual, tópico sin duda inverosímil desde el punto de vista conservador que promueve el género. El mismo inverosímil genérico roza casi el absurdo (y aún el escándalo conceptual) en Utopia gay (1983) de José Rafael Calva, novela donde se narran las venturas y desventuras cotidianas de un matrimonio homosexual que está esperando un hijo propio. Antonio Skármeta, por su parte, también violenta la receta y aprovecha el modelo del melodrama para contar otra historia. En Ardiente paciencia (1985), por ejemplo, el cambio de retóricas que modula el amor de Mario Jiménez y Beatriz González sirve de contrapunto rítmico para escandir la curva histórica que inicia Allende y pone fin Pinochet: convincentemente la novela de Skármeta, que empieza con metáforas nerudianas y sigue con boleros, termina invadida por refranes y prosaísmos cosechados en la enciclopedia culinaria de la madre de Beatriz.

En líneas generales, todo parece indicar que nuestras versiones de la fórmula tratan de escribir en clave melo para colar "valores agregados" al espectro tópico del género. Si es cierto entonces que el modelo tradicional de Trivialliteratur dramatiza utopías de pasaje social, y es cierto también que usa este rédito simbólico para convertir sus textos en un espacio efectivo de integración y cohesión social, cabe entonces pensar que los desarreglos que "normalizan" las versiones defectuosas del género en América Latina, lejos de romantizar las diferencias económico-sociales (como quiere el modelo), parecen más bien resaltar esas mismas diferencias. La novela de fórmula entonces no cree (ni reproduce) las "utopías de pasaje" propias del género, y con este gesto debilita las bases mismas de un modelo que, por un lado, promete realizar el mito de la integración mientras que, por otro, funciona activamente regulandoy restringiendo los contenidos simbólicos de las diferencias sociales.

Cuando el relato de integración y pluralismo gana terreno en el campo político y cultural latinoamericano, sintomáticamente una franja importante de la novela de los 80 se pone a hablar de ghettos. Y hablar de ghettos (esto es, hablar de espacios sociales y culturales discontinuos y cerrados) es otra forma de negar poder de simbolización a los mitos de "pasaje" e integración social. En lo que puede considerarse una instancia más del proceso de secularización o autonomización que venimos describiendo, esta línea narrativa incorpora una lista de figuras marginadas que en su mayoría ya habían sido objeto de estereotipización por parte de las respectivas tradiciones nacionales. Según el mapa vigente de lo social, estas figuras son las que por definición quedan fuera, las que históricamente des-bordan el reparto de bienes económicos y simbólicos, viniendo entre todas a formar un catálogo extenso y relativamente transitado por la literatura latinoamericana. Un catálogo que resulta fácil reconstruir, sobre todo si se tiene en cuenta que incluye grupos económicamente amenazantes, como el indígena, el negro o el judío, o grupos que representan distintas formas de dislocación social como el homosexual, el exiliado, el macró o la prostituta. 
Son, como se dijo, novelas que hablan de ghettos porque niegan la utopía de "pasaje" y, en especial, niegan la utopía del ascenso, que es la que adjunta al pasaje la promesa de la adquisición. Explícitamente los textos tienden a resistir tres de las formas más ritualizadas del pasaje: la asimilación cultural (que involucra el cambio de subjetividad), la integración social (o cambio de clase) y el cruce geográfico (o cambio de territorialidad). Tres umbrales que funcionan como divisorias opacas cada vez que esta versión particular de novela culinaria procede a separar y clasificar los sintagmas según las coordenadas adentro-afuera o arriba-abajo. Por donde se los mire - desde los exiliados de Poli Délano hasta los judíos de Isaac Goldemberg, pasando por los homosexuales de Luis Zapata, los teporochos de Carlos Eduardo Turón o las prostitutas de Enrique Medina-, los espacios ghettificados no constituyen lugares plácidos, ni siquiera conforman cofradías consoladoras. La relación de exterioridad que los territorios centrados mantienen con el ghetto parece confinarlo a una zona de culpa en torno a la cual el ghetto levanta un territorio cohesionado por la paranoia y codificado por una densa semiótica de ritos de identidad y diferenciación: "En tierra de machos" — se lee en Noche de califas (1982) de Armando Ramírez- "lo importante es meterla no sacarla, no sacarle. Meter las manos, el fierro, las patas, la cabeza; la de tu miembro y la de pensar. Todo eso sucedía, era como si en el ambiente estuviera el alfabeto, el aire lleno de signos para hablarse sin necesidad de las palabras, puros gestos, puros ademanes, puras señas, puras mentadas, puros "quién vives"' (35).

Varias marcas pueden servir para territorializar el ghetto. Entre otras, puede pensarse en la fuente productora de diferencia que toma en cuenta la frontera geográfica (y entonces habría que citar el caso de Tepito como territorio exclusivo de muchas novelas de Armando Ramírez). También puede pensarse en el exilio como una marca de desterritorialización lingüística ( $\mathrm{y}$, en este caso, habría que recordar el "bilingüismo" que define, entre otros rasgos, a los personajes exiliados de Poli Délano o Manuel Puig). De igual forma, podrían asimismo enumerarse marcas étnicas o sexuales que sin duda convocarían otros ejemplos y otros autores. Sin embargo, la fuente productora de diferencias más obvias que actúa en la base de la novela de ghetto es, en cualquier caso, el dinero (o, mejor, su ausencia); y en relación inmediata con el dinero, el cuerpo, que actúa como espacio privilegiado donde luchan los valores que desata la transacción comercial de la cual el cuerpo es objeto. La ausencia de "moralidad" que controla las bases económicas de esta relación cuerpo-dinero legitima a su vez el lazo genérico que de manera más o menos voluntaria la novela de ghetto ha venido estableciendo con el modelo picaresco (piénsese, por ejemplo, en la remisión explícita al género que promueven obras como Las aventuras, desventuras y sueños de Adonis García, el vampiro de la Colonia Roma (1979) de Luis Zapata, Flores robadas en los jardines de Quilmes (1980) de Jorge Asís o El entenado (1983) de Juan José Saer). En la medida en que rige la dominante del dinero, estas novelas formulan sus conflictos en términos de relaciones materiales y ponen en marcha una economía centrada en el "interés" a partir de la cual es posible explicar la fascinación que manifiesta la neo-picaresca por tópicos como la prostitución (femenina y masculina), el cuerpo en venta o la pornoviolencia social. Diríase que el registro "naturalista" que ha servido muchas veces para dar forma a este comercio de cuerpos busca des-moralizar o des-estilizar la versión reificada del "bárbaro" que circula en otras redes de sentido, al tiempo que aspira también a recrudecer el componente económico que subyace en la base de todo espacio ghettificado ("Lo soez -_escribe José Luis González- es el acercamiento crítico que se anima a demoler para 
desenmascarar y poder conocer" [14]). Cabe asimismo señalar que muchas de las novelas que plantean este tipo de relaciones comerciales hacia el interior de sus textos (y entre las que es válido incluir obras de Enrique Medina, Jorge Asís, Carlos Eduardo Turón, Luis Zapata o Armando Ramírez), han logrado hacia el exterior un éxito atípico de público contribuyendo de esta manera a masificar la relación que guarda el mercado con la tendencia de punta que vincula a obras y lectores.

El ghetto es, por definición, el escenario que dramatiza la cura del "pasaje:" el lugar que promete sanar la anomia o la pérdida de identidad social, subjetiva o territorial que sigue al pasaje. Como sucede en las obras canónicas de la picaresca tradicional, la anomia social se refleja directamente en el escamoteo del nombre propio del excluído. Muchos de los "nuevos pícaros" tampoco tienen nombre o es lo primero que pierden a lo largo del camino narrativo: el anonimato es, en efecto, lo que define tanto al narrador de El entenado, como a la narradora de La princesa del Palacio de Hierro de Gustavo Sainz o al exiliado que regresa a una patria que no reconoce en Una sombra ya pronto serás (1990) de Osvaldo Soriano. El nombre es también lo primero que pierden los teporochos que circulan en las novelas de Armando Ramírez o es lo primero que quieren borrar los Pechoff, judíos polacos emigrados a la Argentina, protagonistas de la historia fallida de asimilación que Mario Szichman narra insistentemente a lo largo de un ciclo de cuatro novelas. ${ }^{15}$

De una forma u otra, las novelas que hablan de ghettos también hablan de la imposibilidad de salvar el hiato entre espacios ghettificados y mainstream y, al señalar esta imposibilidad, enseñan la falsedad de los mitos de cohesión social que actúan llenando esos vacíos. Por eso el subtexto que actúa en la base de muchas novelas de ghettos también construye un discurso paródico que desmiente las grandes retóricas de legitimación nacionalista. Cuando Mario Szichman cuenta la historia fallida de asimilación de los Pechoff, está desenmascarando al mismo tiempo la dimensión apócrifa de la Argentina como "crisol de razas," mito de cohesión fraguado por la ideología liberal en pleno aluvión inmigratorio. De la misma manera, Moreno-Durán reelabora el mito Colombia: "Atenas Sudamericana" contando la historia nacional como una sucesión exasperante de salones literarios, de erudición sensacionalista y de mandarinatos presididos por damas cultas "a la violeta" ("Lo que pasa es que a este país se lo tiró la mala fama. Eso de la Atenas Suramericana y de los presidentes gramáticos ha resultado más nocivo para nosotros que la Guerra de los mil días, el monocultivo o cualquiera otra calamidad por el estilo" [Juego de damas 142]). En este mismo sentido, la novela de Moreno-Durán juega a ser también una versión (paródica y urbana) de la sacralizada epopeya nacional La vorágine: los peligros o amenazas que encarnan los ghettos del saber femenino resultan sin duda mucho más tiránicos, bárbaros y riesgosos que los peligros simbolizados exitosamente en otros tiempos por la selva devoradora de José Eustasio Rivera. Algo parecido cabe decir también de La vida a plazos de don Jacobo Lerner (1980). En esta novela, Isaac Goldemberg parodia explícitamente el gran relato mítico-liberal que promueve la fe en el progreso a fuerza del "blanqueo" racial. La segregación y la progresiva estupidización de Efraín Lerner, hijo de judío y mestiza, constituye la respuesta sarcástica que la novela es capaz de oponer a este mito que cree en la "superación" racial de América Latina por vía de mestizaje. Explícitamente

${ }^{15}$ Las cuatro novelas del ciclo de Mario Szichman son: Crónica falsa (1969), Losjudios del Mar Dulce (1971), La verdadera crónica falsa (1972) y $A$ las 20,25, la señora entró en la inmortalidad (1981). 
la remisión a este paradigma aparece en la carta que el Dr. José Eugenio Miranda dirige al director de la revista Alma hebrea: "Campo experimental interesante sería la mezcla de esta raza inquieta (la suya) con nuestro indio, la cual daría, por cierto, el tipo ideal del hombre del Andes, porque entonces veríamos hermanadas la resistencia física, la reciedumbre andina, a la agilidad mental judía y a su dinamismo. De aquí surgiría, pienso yo, el hombre nuevo; es decir, el tipo peruano, inconfundible, peculiar, propio" (17).

Frente al fuerte sentido alienador y contestatario que exhala el espacio ghettificado en La vida a plazos de don Jacobo Lerner, el carácter elegiaco con que El hablador (1987) de Mario Vargas Llosa narra tanto la utopía del pasaje como la asimilación del marginado resulta vistosamente atípico y dislocado. Justamente esta resolución extraña a la tendencia general del tópico nos permite leer la novela de Vargas Llosa como contrapropuesta ideológica a la novela de Goldemberg, en particular, y a la novela de ghetto, en general. La doble historia que cuenta Vargas Llosa (dos líneas narradas en primera persona: hipóstasis de Vargas Llosa la primera, e hipóstasis de Saúl Zuratas la segunda) resulta empujar al marginado, elegíaca y externamente, a abrazar un destino de anomia que tiene toda la apariencia de ser un destino gozoso y pertinente. La novela transforma a Saúl Zuratas (que, como Efraín Lerner, es también judío, mestizo y "maculado" por la naturaleza) primero en Mascarita, y luego lo convierte románticamente en mítico hablador de los machiguengas, tribu indígena en extinción al lado de la cual el triple marginado espera la disolución en un destino común que tarde o temprano vendrá de la mano del "inevitable progreso." Tanto las palabras hipostasiadas del hablador que "se parecen a una mala novela indigenista" (Rowe 64), como la hipostasiada autodesaparición (pacífica y tranquilizadora) que protagonizan los marginados en El hablador, permite concluir que Vargas Llosa metaboliza los hiatos o las diferencias sociales y económicas a través de ritos de conversión donde "lo distinto se hace soluble, digerible" (García Canclini 174). En otras palabras, Vargas Llosa estiliza, normaliza y transforma en puro virtuosismo electivo el principio de exclusión que actúa efectivamente en la base de todo espacio ghettificado. Para ello, apela a una estrategia que recuerda, sospechosa aunque previsiblemente, el rito de evaporación que Ricardo Güiraldes hace protagonizar al gaucho argentino en Don Segundo Sombra.

Viejos contenidos en nuevos enlatados: la versión legendaria, sentimental y doblemente fotogénica del agente social marginado ${ }^{16}$ que propone la novela de Vargas Llosa reproduce sin alterar los componentes biológico-telúricos presentes en la definición de lo popular que la ideología de losEstados oligárquicos distribuyó exitosamente en épocas pasadas por toda América Latina. ${ }^{17}$ De acuerdo a la gramática de reciclado que rige parte de la cultura

\footnotetext{
${ }^{16}$ La versión de lo popular que ofrece $E l$ hablador es "doblemente fotogénica," en primer lugar, por los procesos de estetización al que Vargas Llosa somete al/ los marginado/s en la novela. En segundo lugar, porque es justamente a través de la fotografía (medio que entrega una imagen congelada y mediatizada) donde se produce el último "contacto" entre el narrador y Saúl Zuratas y los machiguengas.

${ }_{17} \mathrm{Al}$ definir las distintas concepciones politicas de lo popular, García Canclini se refiere a la concepción "biológico-telúrica" en los siguientes términos: "surgí́ como ideología orgánica de los estados oligárquicos y sobrevive en movimientos nacionalistas de derecha. Define a la nación como un conjunto de individuos unidos por lazos naturales - el espacio geográfico, la raza - e irracionales —el amor a una misma tierra, la religión — sin tomar en cuenta las diferencias sociales" $(1984,26)$.
} 
neoliberal, El hablador recupera viejos contenidos morales presentes ya en el melodrama tradicional (i.e., fatalismo, paternalismo, idealismo, defensa del status quo) y los entrega bajo un nuevo formato aprovechando el efecto-shock que deriva de su inmersión en el flujo del espectáculo. Esta lógica inscribe ideológicamente la obra de Vargas Llosa dentro de lo que la crítica llama genéricamente "novela posmoderna" (Franco 1991). En contraste con este modelo genérico, las novelas culinarias o las versiones latinoamericanas de Trivialliteratur que se han revisado hasta este punto proceden por resistencia y adjunción de contenidos. Ajenas a esta concepción de reciclado que urge a producir "lo mismo en envase diferente" (según prescribe la gramática posmoderna), la novela culinaria tiende contrastantemente a generar nuevos enunciados (sociales, culturales e ideológicos) adjuntándolos a viejos formatos. En este punto entonces radica la diferencia entre la moral negativa o contestadora que propone la novela culinaria en Latinoamérica y la ideología positiva, legitimadora y neoconformista que distribuye la variante posmoderna de cierta narrativa contemporánea. Una diferencia que debe leerse en el uso específico de los enunciados y no en el uso retórico de los formatos. Los medios en sí nunca dicen nada. Son instrumentos neutros, por eso resultan una oferta disponible a políticas de apropiación simbólica que no siempre son compatibles ideológicamente entre sí.

\section{OBRAS CitADAS}

Aira, César. Copi. Buenos Aires: Beatriz Viterbo Editora, 1991.

Aguilera Garramuño, Marco Tulio. Breve historia de todas las cosas. Buenos Aires: Ediciones de la Flor, 1975.

Alvarez Gardeazábal, Gustavo. Pepe Botellas. Bogotá: Plaza \& Janés, 1984.

Arguedas, José M. y Cortázar, Julio. "Polémica entre dos escritores". Marcha 1450 (30 de mayo de 1969): 29-30.

Baudrillard, Jean. Las estrategias fatales. Barcelona: Anagrama, 1984.

Benjamin, Walter. Discursos interrumpidos I. Madrid: Taurus, 1973.

Berman, Marshall. All That Is Solid Melts Into Air. New York: Simon and Schuster, 1982.

Collazos, Oscar, Julio Cortázar y Mario Vargas Llosa. Literatura en la revolución y revolución en la literatura. México D.F.: Siglo XXI, 1970.

Cortázar, Julio. La vuelta al día en ochenta mundos. México: Siglo XXI, 1967. . Libro de Manuel. Buenos Aires: Sudamericana, 1973.

Franco, Jean. "¿La historia de quién? La piratería postmoderna". Revista de Crítica Literaria Latinoamericana 33 (1991): 11-20.

Foley, Barbara. Telling the truth. The Theory and Practice of Documentary Fiction. Ithaca: Cornell University Press, 1986.

Forgues, Roland. Palabra viva. Tomo I. Narradores. Lima: Studium, 1988.

García Canclini, Néstor. "¿De qué estamos hablando cuando hablamos de lo popular?". Punto de vista 20 (1984): 26-31.

. Culturas hibridas. Estrategias para entrary salir de la modernidad. México D.F.: Gijalbo, 1990.

García Márquez, Gabriel. El general en su laberinto. Bogotá: Editorial Oveja Negra, 1989.

Gilly, Adolfo. "Nuestra caída en la modernidad". Nexos 101 (1986): 21-32. 
Goldemberg, Isaac. La vida a plazos de don Jacobo Lerner. Hanover: Ediciones del Norte, 1980.

González, José Luis. “Apuntación mínima de lo soez”. Literature and Popular Culture in the Hispanic World. Ed. Rose Minc. Gaithersburg: Hispamérica, 1981.

Habermas, Jurgen. "La crisis del estado-providencia y el agotamiento de las energías utópicas". Los Cuadernos del Norte 38 (1986): 30-38.

Halperín Donghi, Tulio. "El presente transforma el pasado: el impacto del reciente terror en la imagen de la historia argentina". Ficción y política. La narrativa argentina durante el proceso militar. Eds. David Foster, Daniel Balderston, Tulio Halperín Donghi, Francine Masiello, Marta Morello-Frosch, Beatriz Sarlo. Buenos Aires: Alianza Editorial, 1987.

Hollowell, John. Fact \& Fiction. The New Journalism and the Nonfiction Novel. Chapel Hill: The University of North Carolina Press, 1977.

Jameson, Fredric. "De la sustitución de importaciones literarias y culturales en el Tercer Mundo: El caso del testimonio". Revista de Crítica Literaria Latinoamericana 36 (1992): 117-133.

Jauss, Hans R. La literatura como provocación. Barcelona: Ediciones de Bolsillo, 1976. Kundera, Milan. Immortality, trans. Peter Kussi. New York: Grove Weidenfeld, 1990.

Larsen, Neil. Modernism and Hegemony. A Materialist Critique of Aesthetic Agencies. Minneapolis: University of Minnesota Press, 1990.

Leñero, Vicente. Los periodistas. México D.F.: Joaquín Mortiz, 1978.

Ludmer, Josefina. El género gauchesco. Un tratado sobre la patria. Buenos Aires: Sudamericana, 1988.

Mandel, Ernest. Crimen delicioso. Historia social del relato policiaco. Textos de Ciencias Sociales, Trans. Pura López Colomé. México D.F.: Universidad Nacional Autónoma de México, 1986.

Moreno-Durán, Rafael Humberto. Juego de damas. Barcelona: Seix Barral, 1977.

Piglia, Ricardo. Respiración artificial. Buenos Aires: Pomaire, 1980. Crítica y ficción. Buenos Aires: Siglo Veinte, 1990.

Rama, Ángel. “Ángel Rama tira la piedra ..." . Zona franca 14 (1972a): 15-17. "Carta de Ángel Rama a Zona franca". Zona franca 16 (1972b): 9-15.

. La novela en América Latina. México: Universidad Veracruzana, 1986.

Ramírez, Armando. Noche de califas. México D.F.: Grijalbo, 1982.

Rowe, William. "Una lectura política de Vargas Llosa". Revista de la Universidad Nacional Autónoma de México 480-481 (1990): 59-64.

Ruffinelli, Jorge, Antonio Pino Méndez, Luis Arturo Ramos y Juan Ventura Sandoval. "Los escritores mexicanos ante su realidad". Hispamérica 11-12 (1975): 33-48.

Ruffinelli, Jorge. “Los 80: ¿Ingreso a la posmodernidad?”. Nuevo Texto Crítico 6 (1990): 31-42.

Sarlo, Beatriz. El imperio de los sentimientos. Buenos Aires: Catálogos, 1985. "Un debate sobre la cultura". Nueva Sociedad 116 (1991): 88-93.

Sigal, Silvia. Intelectuales y poder en la década del sesenta. Buenos Aires: Puntosur, 1991. Soriano, Osvaldo. Rebeldes, soñadores y fugitivos. Buenos Aires: Editora/12, 1987. 
Stavans, Ilán. "An Appointment with Héctor Belascoarán Shayne, Mexican Private Eye. (A Profile of Paco Ignacio Taibo II)". Review: Latin American Literature and Arts 42 (1990): 5-9.

Subercaseaux, Bernardo. Historia, Literaturay Sociedad. Santiago: Ediciones Documenta, 1991.

Taibo II, Paco Ignacio. "La 'otra' novela policíaca". Los cuadernos del Norte 41 (1987): 36-41.

Taibo II, Paco Ignacio. La vida misma. México, 1987.

Vargas Llosa, Mario. El hablador. Barcelona: Seix Barral, 1988.

Viñas, David. "Después de Cortázar: historia y privatización". Cuadernos Hispanoamericanos 234 (1969): 734-739.

. Literatura argentina y realidad politica. De Sarmiento a Cortázar. Buenos Aires: Ediciones Siglo Veinte, 1971.

. "Pareceres y digresiones en torno a la nueva narrativa latinoamericana". Más allá del boom. Literatura y mercado. Ed. Ángel Rama. Buenos Aires: Folios, 1984.

Zermeño, Sergio. "La tentación posmoderna". Nexos 124 (1988): 5-8.

"Los intelectuales y el Estado en la década perdida". Revista Mexicana de Sociologia 3 (1990): 213-235.

\section{ADDENDA BiBLIOGRÁFICA}

Agosín, Marjorie. "Literatura y derechos humanos en Latinoamérica". Plural 205 (1988): 48-54.

Ainsa, Fernando. "La nueva novela histórica latinoamericana". Plural 240 (1991): 82-85.

Antezana, Luis H. "La novela boliviana en el último cuarto de siglo". Tendencias actuales en la literatura boliviana, Ed. Javier Sanjinés C. Minneapolis: Institute for the Study of Ideologies \& Literature, 1985)

Araújo, Helena. "La novela colombiana en la década del '70". Eco 230 (1980): 160-174. Blanco, José Joaquín. “Aguafuertes de narrativa mexicana, 1950-1980”. Nexos 56(1982): 23-39.

Cano Gaviria, Ricardo. "La novela colombiana después de García Márquez". Manual de literatura colombiana. Tomo II. Bogotá: Ed. Procultura, 1988.

Cánovas, Rodrigo. "Una reflexión sobre la novelística chilena de los años 80". Revista Chilena de Literatura 38 (1991): 101-108.

Castañón, Adolfo. "Y tus hombres, Babel, se envenenarán de incomprensión ... (la narrativa mexicana en los sesenta)". Siempre! (28 de abril de 1976): 2-10.

Concha, Jaime. "Testimonios de la lucha antifascista". Casa de las Américas 112 (1979) 95-105.

Domínguez Michael, Christopher. "Notas sobre mitos nacionales y novela mexicana (1955-1985)". Revista Iberoamericana 148-149 (1989): 915-924.

Domínguez Michael, Christopher. "Introducción". Antología de la narrativa mexicana del siglo XX (México: Fondo de Cultura Económica, 1991).

Fajardo, Diógenes. "La narrativa colombiana de laúltima década: Valoración y perspectivas". Revista Iberoamericana 141 (1987): 887-901. 
Franco, Jean. "Pastiche in Contemporary Latin American Literature". Studies in 20th Century Literature 14.1 (1989): 95-107.

Fuentes, Carlos. "Los hijos de Don Quijote". Nexos 157 (1991): 43-51.

Giardinelli, Mempo. "Panorama de la narrativa mexicana en los 80's". Insula 512-513 (1989): 22-24.

Jaramillo Zuluaga, J.E. "Alta tra(d)ición de la narrativa colombiana de los ochenta". Boletín cultural y bibliográfico 15 (1988): 71-83.

Jiménez P., David. "La novela colombiana (1985-1989)". Insula 512-513 (1989): 27-29.

Klahn, Norma. "Un nuevo verismo: Apuntes sobre la última novela mexicana". Revista Iberoamericana 148-149 (1989): 925-935.

Merrel, Floyd. "Lacifra laberíntica: Más allá del 'Boom' en México". Revista Iberoamericana 150 (1990): 49-59.

Monsiváis, Carlos. "Los de atrás se quedarán (I). Cultura y sociedad en los 70". Nexos 26 (1980): 35-43.

. "Los de atrás se quedarán (II). Cultura y sociedad en los 70". Nexos 28 (1980): 1123.

- "Cultura urbana y creación intelectual. El caso mexicano". Cultura y creación intelectual en América Latina. Ed. Pablo González Casanova. México: Siglo XXI, 1984.

Ortega, Julio. “La literatura latinoamericana en la década del 80”. Eco 215 (1979): 535-540. "El postmodernismo en América Latina". Homenaje a Alfredo Roggiano. En este aire de América. Eds. Keith McDuffie y Rose Minc. Pittsburgh: Instituto Internacional de Literatura Iberoamericana, 1990.

Promis, José. "Balance de la novela en Chile: 1973-1990". Hispamérica 55 (1990): 15-16.

Ruffinelli, Jorge. "Notas sobre la novela en México (1975-1980)". Cuadernos de Marcha (1981): 47-59.

Schneider, Luis Mario. "El tema homosexual en la nueva narrativa mexicana". Casa del tiempo 49-50 (1985): 82-86.

Skármeta, Antonio. "Narrativa chilena después del golpe". Casa de las Américas 112 (1979): 83-94.

Sosnowski, Saúl. "La dispersión de las palabras: Novelas y novelistas argentinos en la década del setenta". Revista Iberoamericana 125 (1983): 955-963.

Torres, Vicente Francisco. Esta narrativa mexicana. Ensayos y entrevistas. México: Leega, 1991.

Valencia Solanilla, César. "La novela colombiana contemporánea en la modernidad literaria". Manual de literatura colombiana. Tomo II. Bogotá: Procultura, 1988. 